\title{
Hacia una historia comparada de los pueblos de indios de San Joseph y San Marcos en la jurisdicción de Córdoba, siglo XVIII: autoridades, población, tierras y tributo
}

Magdalena Schibli"

Fecha de recepción: 9 de mayo de 2018. Fechas de aceptación: 23 de agosto de 2018

\section{Resumen}

En este trabajo abordamos los procesos de resistencia y adaptación de los pueblos de indios de la jurisdicción de Córdoba en la Gobernación del Tucumán, durante el siglo XVIII. Analizaremos particularmente dos casos, San Marcos y San Joseph, que se prestan para un análisis a contrapunto: ambos se conformaron en situaciones similares pero a medida que avanzó el siglo XVIII sus historias fueron separándose. Mientras que San Joseph se ocupó de la defensa de la frontera oriental de la jurisdicción, conformando una milicia de indios soldados, el pueblo de San Marcos sostuvo con constancia el entero del tributo y la entidad numérica del pueblo. Nos ocupamos de analizar las situaciones particulares de cada uno, a los fines de comprender por qué San Marcos logró mantener el reconocimiento oficial de sus tierras y de su comunidad, mientras que San Joseph desapareció de los registros de pueblos de indios tributarios.

Towards a comparative history of the indian towns of San Joseph and San Marcos in Cordoba's jurisdiction, $18^{\text {th }}$ century: authorities, population, land and tribute

\begin{abstract}
In this paper we approach the process of resistance and adaptation of pueblos de indios (indian towns) of the jurisdiction of Cordoba in the Government of Tucumán, during the 18th century. We will particularly analyse two towns, San Marcos and San Joseph, presented here for a counterpoint study: both cases were defined in similar conditions but their history torn apart as the 18th century advanced. While San Joseph dealt with the defence of the jurisdiction's
\end{abstract}

Palabras clave

pueblos de indios tierras

tributo

Key words

indian towns

land

tribute

* Escuela de Historia, Facultad de Filosofía y Humanidades, Universidad Nacional de Córdoba. Área de Historia, Centro de Investigaciones de la Facultad de Filosofía y Humanidades, Facultad de Filosofía y Humanidades, Universidad Nacional de Córdoba. Villa Parque Santa Ana, Córdoba, Argentina. E-mail: mag.schibli@gmail.com 
1. Tomamos la noción de "pacto de reciprocidad" de Tristan Platt; hacemos referencia al pacto que implicaba la obligación de la Corona en reconocer y garantizar el acceso a la propiedad comunal de las tierras de parte de la sociedad indígena, aceptando como contraparte el pago de un tributo (Platt, 1982: 20). oriental border, shaping a militia of indian soldiers, the town of San Marcos kept with constancy the entire amount of tribute and the numerical entity of the town. We analyse the specific situation of each one, in order to understand why San Marcos managed to kept the official recognition of its lands and its community, while San Joseph disappeared from the tributary Indian town records.

\section{Introducción}

El punto de partida de este artículo son los procesos de resistencia y adaptación de los pueblos de indios de la jurisdicción de Córdoba ya que, en las últimas décadas del periodo colonial, solo diez de ellos permanecían reconocidos en las listas de tributarios: Nono, Soto, Pichana, La Toma, San Marcos, Cosquín, Quilino y San Antonio de Nonsacate (Tell y Castro Olañeta, 2011: 245). A este grupo debemos sumar al pueblo de San Joseph pues si bien fue registrado en 1775 por última vez como pueblo de indios tributarios, encontramos otras referencias documentales que dan cuenta de su pervivencia, con posesión de sus tierras comunales, hasta fines del periodo colonial. Sin embargo, de este grupo, solo seis mantuvieron el reconocimiento oficial como comunidades indígenas hasta 1880, cuando el Estado provincial expropió y subdividió sus tierras (Tell y Castro Olañeta, 2011: 235).

En este marco, trabajaremos de manera comparativa con dos pueblos de indios con una larga historia de pervivencia: San Joseph y San Marcos. Reconstruir la historia de estos pueblos de indios tiene el propósito de aportar a nuestro conocimiento acerca de los procesos de transformación y resistencia a lo largo del siglo XVIII, y analizar cómo los caminos divergentes que cada uno tomó repercutieron en sus historias, ya que mientras San Marcos se presenta como un caso exitoso de reconocimiento de sus derechos hasta fines del periodo colonial e incluso se sostiene hasta 1880, San Joseph desaparece de los registros hacia 1804.

Así, analizaremos ambos casos poniendo en juego tanto su historia en común, como las diferencias en torno a las situaciones particulares que el pacto de reciprocidad ${ }^{1}$ tomó en cada caso. Se trata de dos pueblos que se prestan para un análisis a contrapunto, en tanto ambos se constituyeron a partir de encomiendas de indios desnaturalizados provenientes de los valles Calchaquíes, y fueron sometidos a sucesivos traslados y relocalizaciones hasta que, en 1694, el oidor Luján de Vargas ordenó que se les señalaran tierras propias. Asimismo, ambos pueblos a fines del periodo colonial debieron llevar a instancias judiciales la defensa de sus derechos a las tierras, enfrentándose a intereses de autoridades y vecinos españoles.

A pesar de estas similitudes, a lo largo del siglo XVIII sus historias fueron apartándose: mientras que el pueblo de indios de San Joseph, ubicado en la región de llanura este, se ocupó de la defensa de la frontera de la jurisdicción, conformando una milicia de indios soldados; el pueblo de San Marcos, ubicado en la región de las sierras, sostuvo con constancia el entero del tributo y la entidad numérica del pueblo. Así, nos ocuparemos de analizar las situaciones particulares de cada uno, considerando también el rol que cumplieron las autoridades indígenas de cada pueblo, sobre todo en la coyuntura de fines del periodo colonial cuando debieron defender sus tierras. 
Los casos elegidos también nos permiten reflexionar sobre las repercusiones que su presencia y/o ausencia en los registros coloniales tuvo al momento de buscar el reconocimiento de la Corona a instancias de los juicios por sus tierras, lograr fallos a su favor y, por tanto, sostener sus derechos como pueblos de indios.

\section{Historias en común: la conformación de los pueblos de San Marcos y San Joseph}

Los dos casos que abordamos en este trabajo se conformaron a partir de las mismas coyunturas. En primer lugar, tanto para reconstruir la historia de San Marcos como la de San Joseph debemos remontarnos a las guerras en los valles Calchaquíes ya que un número importante de sus habitantes provenían de encomiendas de indios desnaturalizados de esos valles. En este sentido, sabemos gracias a la investigación de Virginia Zelada (2017) que Alonso Luján de Medina recibió en Córdoba una encomienda de indios yocaviles, a partir de un mecanismo singular y llamativo ya que los indios desnaturalizados llegaron a manos de un vecino cordobés -que hasta el momento no era encomendero y además no había participado de la campaña de pacificación de los valles. La encomienda de doce familias yocaviles -un tercio de la parcialidad- había sido entregada por primera vez, en 1667, por el Gobernador Mercado y Villacorta, a Bartolomé de Olmos y Aguilera en retribución por los servicios prestados en la campaña en los valles Calchaquíes. Fue asignada a La Rioja, pero Olmos y Aguilera no sólo residía en Córdoba sino que allí también tenía una encomienda de indios originarios por lo que decidió, en un primer momento, asentar a las familias yocaviles en chacaras de vecinos riojanos. No obstante, renunció en 1670 a esta encomienda e inmediatamente pidió que le fueran restituidas las doce familias para ser otorgadas a su yerno, Alonso Luján de Medina en primera vida. El gobernador Ángel de Peredo atendió a este pedido y en 1670 reasignaron la encomienda yocavil a Alonso Luján de Medina, permitiendo que la traslade a Córdoba (Zelada, 2017: 89-90). Podemos ver, entonces, que este caso devela una estrategia para extender el goce de la encomienda en manos de una familia, pues don Bartolomé Olmos y Aguilera la renunció en primera vida a favor de su yerno, Luján de Medina, quien la recibió también en primera vida.

Por su parte, el pueblo de indios de San Joseph también se conformó a partir de la reducción de una encomienda de ocho familias desnaturalizadas de los valles Calchaquíes. Gerónimo de Funes y Ludueña había participado junto a su hijo Christobal en las campañas militares de los valles Calchaquíes, razón por la cual recibió una encomienda de indios quilme en primera vida en 1665, mientras su hijo Christobal de Funes y Ludueña la recibió en segunda vida en 1688. Además, Christobal había recibido otra familia en primera vida, por su participación en la asistencia de la última campaña calchaquí (Zelada, 2017: 94-95).

Otro momento que nos permite hablar de la historia en común de San Marcos y San Joseph es la visita del oidor Luján de Vargas en 1693, la cual constituye una coyuntura favorable de reconocimiento de los derechos de los pueblos de indios. En efecto, al momento de la llegada de este funcionario a la jurisdicción de Córdoba ambas comunidades se encontraban asentadas en las estancias de sus encomenderos, sin tierras propias asignadas y prestando servicio personal a sus encomenderos. Como consecuencia, el visitador general de Charcas dictó sentencias con el objetivo de desagraviar a los indios, que incluían la demarcación 
de las tierras en función de la cantidad de indios de tasa -para lo cual, además, los empadronó-, la asignación u orden de construir una capilla propia y el pago de las deudas a aquellos indios que hubieran prestado servicios personales sin ser remunerados. En la jurisdicción de Córdoba, Luján de Vargas comisionó a Manuel Ceballos Neto y Estrada para ejecutar sus sentencias. De esta manera, para ambas encomiendas se señalaron y delimitaron las tierras de reducción que corresponderían a cada pueblo de indios, configurando una instancia fundamental de formación de derechos a las mismas (Castro Olañeta, 2015: 3).

Sin embargo, como veremos en el apartado siguiente, conforme avanzó el siglo XVIII sus caminos comenzaron a separarse. A pesar de que a fines del periodo colonial ambas comunidades encabezaron juicios para defender sus derechos a las tierras del pueblo de indios, solo San Marcos logró obtener una sentencia favorable. Como contrapartida, San Joseph fue desconocido por las autoridades de la gobernación intendencia, al punto que dio lugar al establecimiento de una villa de españoles en las mismas tierras. En este sentido, creemos que los resultados de negociaciones que los habitantes de estos pueblos de indios lograron en torno a sus obligaciones como vasallos de la Corona y las distintas estrategias implementadas en estos pueblos para cumplimentar tales obligaciones -conforme avanzó el siglo XVIII- devinieron en situaciones particulares que se convirtieron en un aspecto fundamental para su reconocimiento como tal a fines del siglo, en una coyuntura signada por el avasallamiento de los derechos comunales sobre sus tierras.

\section{Caminos que se abren: población, tierra y tributo}

Si bien la intervención de Luján de Vargas en la Jurisdicción de Córdoba vino a desagraviar a los indios y hacer cumplir las Ordenanzas de Alfaro, recordando a los encomenderos que los indios eran vasallos de la Corona y consolidando el contrato basado en la obligación de asignar tierras a los indios a cambio de que paguen un tributo cuyo monto fue tasado (Castro Olañeta, 2015: 11), a medida que avanzó el siglo XVIII, el funcionamiento de este contrato en los casos de San Marcos y San Joseph adquirió distintos contenidos.

Como mencionamos, el pueblo de San Marcos constituye uno de los casos de pervivencia y sostenimiento del reconocimiento oficial de sus derechos a las tierras. Para comprender esto debemos considerar un conjunto de variables que incluyen el crecimiento demográfico sostenido, situación que le permitió garantizar el pago del tributo con cierta regularidad durante todo el siglo XVIII, incluso en el momento de transición de encomiendas privadas a tributarios en cabeza de la Corona (Schibli, 2016).

La información provista por los censos de población y padrones de este pueblo nos permiten afirmar que no estuvo ajeno a la situación de crecimiento demográfico consignado para la totalidad de la jurisdicción en la segunda mitad del siglo XVIII (Celton, 1993: 19-20; Arcondo, 1992: 174-175; Tell, 2008: 55) y que, además, protagonizó un crecimiento considerable durante todo el siglo, después de una caída importante en los últimos años del siglo XVII. Mientras que en 1693 la encomienda tenía 32 indios, en 1704 solo contaba con

2. FDPC. Padrón de indios tributarios 1704, Doc. 3357.
12 indios. $^{2}$ No obstante, en las últimas décadas del siglo se registraron más de 200 habitantes, que podemos suponer vivían de manera permanente o temporal en el pueblo (Schibli, 2016). 
Aun considerando las deficiencias y heterogeneidad de los registros se trata de uno de los pueblos de indios de la Jurisdicción de Córdoba con más crecimiento de población registrada -si no el de mayor cantidad-, y hacia fines de siglo se contaba entre los de tamaño intermedio dentro de la jurisdicción (Ferrero, 2017). Siguiendo el análisis de la revisita borbónica de 1785, realizado por Paula Ferrero (2017), y relacionándolo con nuestros propios datos más tempranos podemos inferir que el significativo crecimiento demográfico que protagonizó estuvo relacionado, en buena medida, con la incorporación de población foránea, algo que se refleja en esa revisita: en un 55\% de población con origen externo consignado y un $66 \%$ de uniones exogámicas -donde uno o ambos miembros eran nacidos fuera del pueblo. Estas incorporaciones no eran tan recientes y en varios casos habían tributado antes, o fueron incorporados "con la venia del gobernador" (Ferrero, 2017: 80, 164). Estos foráneos procedían -en pequeños números- de distintos parajes del curato de Punilla, o cercanos, así como de jurisdicciones vecinas como Catamarca y Santiago del Estero (Ferrero, 2012: 95-96).

Además, así como el pueblo de San Marcos fue el caso que más población foránea recibió fue también uno de los pueblos de indios donde se registró menor cantidad de ausentes cuyo destino fue, en su mayoría, dentro de la jurisdicción, lo que permite suponer la posibilidad de un fácil retorno (Ferrero, 2017: 82-86). En este sentido, a partir de los lugares de procedencia de los foráneos y de destino de los ausentes, Ferrero sostiene que es posible identificar un nodo constituido por cuatro pueblos de indios de la zona (Soto, Pichana, San Antonio y San Jacinto [por San Marcos]) $)^{3}$ en el que San Marcos habría tendido a funcionar como receptor de población junto a Soto, en tanto San Antonio y Pichana habrían tendido a expulsar población (Ferrero, 2017: 90).

La investigación de Ferrero, además, nos provee información referida a la composición interna del pueblo de indios, teniendo como referencia las categorías usadas por las revisitas borbónicas de 1785 y 1792: originarios y forasteros con tierras, forasteros sin tierras, mestizos, mulatos y negros. Ya dijimos que San Marcos presentaba una presencia muy significativa de matrimonios con uno o sus dos miembros externos al pueblo. Hacia 1792 el número de originarios y forasteros con tierras creció en base al traslado interno de estas familias hacia esa categoría. Según la autora estos pasajes de una categoría a otra nos permiten acercarnos a la comprensión de los procesos de integración de población foránea a los pueblos de indios, contribuyendo a su reproducción y supervivencia, en tanto contrarrestaron los efectos disgregadores del ausentismo y del forasterismo. Además, el hecho de reforzar el núcleo de originarios y forasteros con derecho a tierras del común puede interpretarse como una estrategia para mantener la carga colectiva del entero del tributo, permanecer registrados $\mathrm{y}$, de esta manera, sostener el derecho de acceso a las tierras comunales (Ferrero, 2017: 96).

En relación a esto, debemos aclarar que a partir de la vigencia de la Real Ordenanza de Intendentes del Río de la Plata (1782)- en adelante, ROI-, el ramo del tributo se había modificado. La confección de padrones de tributarios no podría hacerse sino cada cinco años, al momento de las revisitas, cuando se registraría el número de indios de tasa y el monto total que debía enterar cada pueblo; es decir que esta situación solo podría modificarse con una nueva revisita. Además, la entrega de un monto total, como carga colectiva, de la que debía hacerse cargo el curaca del pueblo constituía "una novedad para el espacio tucumano, donde el tributo desde la sanción de las ordenanzas de Alfaro fue fijado como una carga individual que se calculaba por cabeza y no
3. A lo largo del siglo XVIII el pueblo de indios de San Marcos también fue denominado San Jacinto. En este trabajo optamos por San Marcos, en tanto es el nombre con el que sus propios habitantes se identifican y que finalmente fue reconocido por la justicia colonial, a fines del siglo. 
4. En 1749, Estanislao Toledo Pimentel era, desde hacía cuatro años, administrador de la encomienda, en coincidencia con el tiempo que hacía que él había heredado la estancia de San Marcos.

5. AHPC, Hacienda 4 (1765-1770) y Hacienda 11 (1772).

6. El sínodo al doctrinero se pagaba de la recaudación del tributo. se asumía colectivamente como ocurría en Andes" (Ferrero, 2017: 103). Por último, a partir de estas modificaciones quedaba abierta a la costumbre de cada lugar el cobro del tributo a las castas.

Lo interesante aquí es la estrategia que el pueblo de indios desarrolló en coincidencia con el interés fiscal que perseguían estas modificaciones, aunque creemos que la incorporación de castas para hacer frente al pago del tributo fue anterior a la ROI, en tanto, en San Marcos, los foráneos identificados por los recaudadores como mestizos o afromestizos ya tributaban al momento de su puesta en vigencia, según consta en un informe del recaudador del ramo del tributo fechado en 1770 (Tell, 2012: 14).

La información trabajada por Ferrero a partir de las visitas borbónicas nos brinda elementos para pensar en la estrategia implementada por los habitantes del pueblo de indios. La incorporación de población foránea no solo permitió sostener su entidad numérica, sino también reemplazar a los indios originarios por recién llegados para hacer frente al entero del tributo. De hecho, Ferrero nos advierte que San Marcos mantuvo una evolución siempre positiva del número de tributarios, dado que las incorporaciones cubrieron la totalidad e incluso superaron las pérdidas de indios tributarios (Ferrero, 2017: 154-155). Del mismo modo, también el porcentaje de los registrados en la categoría originarios con tierras fue creciendo: "en 1792 tenía el porcentaje más bajo de originarios con tierras, junto con Nono, esta categoría creció mucho hacia 1804 (66\%) y de nuevo entre 1804 y 1807 (30\%), para luego caer un poco entre 1807 y 1809 (19\%)". (Ferrero, 2017: 159).

Estos datos nos llevan a preguntarnos si se trata de un esfuerzo planificado por los habitantes del pueblo de indios, conscientes de la importancia de cumplimentar su deber como tributarios para así sostener el goce de los derechos sobre las tierras y mantener su gobierno y representación mediante sus autoridades indígenas. Nos resulta interesante resaltar que se trata de uno de los pocos casos -junto con Soto, Cosquín, Pichana y San Antonio de Nonsacate- en que observamos una constancia en el pago del tributo, no solo con posteridad a las reformas borbónicas y en consonancia con sus objetivos fiscales: se trata de una práctica que podemos identificar desde que la encomienda vacó; es decir, durante el proceso de conversión de encomienda privada a tributarios en cabeza de la Corona. Si bien no tenemos claridad sobre este proceso, los comprobantes de los registros de hacienda dan cuenta de que los indios de San Marcos -con el topónimo San Jacinto- tributaron, a partir de 1749, por medio de su administrador Estanislao Toledo Pimentel. ${ }^{4}$ Posteriormente, lo hemos encontrado, en conjunto con los pueblos recién mencionados, en los registros de los años 1764 y $1772 .{ }^{5}$ Junto al pago del tributo, se consignó también con bastante regularidad en los libros de la Real Hacienda, el pago -a partir de la recaudación del ramo del tributo- del sínodo al cura de Punilla, quien cumplía la función de doctrinero de San Marcos, Soto, Pichana y Cosquín. ${ }^{6}$

Creemos que el hecho de haber sostenido el pago del tributo en esta coyuntura de transición de encomiendas privadas a pueblos de indios en cabeza de la Corona fue fundamental para obtener el reconocimiento del pueblo de indios y sus derechos $\mathrm{y}$, consecuentemente, haber sido registrados como tales por los funcionarios encargados de implementar las modificaciones diseñadas por las autoridades borbónicas.

La importancia de la regularidad del pago puede comprenderse con mayor claridad si lo pensamos comparativamente. Así, a pesar de sus conformaciones 
similares, el caso del pueblo de indios de San Joseph se presenta con una situación completamente diferente. Como encomienda de Christobal de Funes y Ludueña, aparece con el nombre "San Joseph" en los padrones de tributarios de los años 1704 y 1733, ${ }^{7}$ cuando la encomienda ya estaba vaca. Recién lo volvemos a encontrar en el padrón de $1774{ }_{,}^{8}$ cuando aparece por primera vez con la denominación "Compañía y pueblo de indios Los Ranchos". Posteriormente, aunque en el Censo General de población de $1778^{9}$ fueron registrados como pueblo de indios, dejamos de encontrarlos en los documentos de tributarios; es decir, que el pueblo no fue incluido en la revisita borbónica de $1785 \mathrm{ni}$ en 1792. Esta desaparición en los padrones y revisitas fue, en efecto, uno de los argumentos usados por Antonio Rodríguez, vecino del pueblo, para intentar avanzar sobre las tierras que denunciaba como vacas en un expediente iniciado en 1790, cuando hacía referencia a "haverse acabado los expresados indios como es publico y notorio y le consta a VS por las matriculas que se han hecho para la recaudacion de los reales tributos". ${ }^{10}$

No obstante, al analizar los padrones y el censo de población salta a la vista que San Joseph también asistió a un importante crecimiento demográfico a lo largo del siglo XVIII, y que este crecimiento también estuvo relacionado con la incorporación de población foránea. Si bien en el Censo de 1778 toda la población aparece registrada bajo la condición de indios, sabemos por los padrones anteriores que el pueblo también había integrado a población originaria de otros pueblos de indios, mestiza y castas. ${ }^{11} \mathrm{~A}$ pesar de este crecimiento demográfico, a medida que avanzó el siglo XVIII el pueblo de indios de San Joseph presentó algunas particularidades que nos llevan a preguntarnos sobre los recorridos diferentes de estos pueblos.

Para analizar su historia, es necesario partir de las memorias recogidas de los testimonios que fueron tomados con motivo del juicio por las tierras del pueblo, a fines del siglo XVIII y principios del XIX. Estos testimonios nos brindan información valiosa sobre el recorrido de San Joseph, fundamentalmente en relación a su participación en la defensa de la frontera este de la jurisdicción durante la primera mitad del siglo, como Compañía de indios soldados. Más aun, según estos relatos los habitantes de este pueblo de indios habrían sido exonerados del pago del tributo a cambio de cumplir estas funciones. Si bien no tenemos precisiones sobre los años en que se habría implementado este cambio, la situación resulta más que plausible si consideramos la conflictividad de esa frontera entre la tercera y la quinta década del siglo XVIII. ${ }^{12}$

Así es que entre los testimonios de los vecinos se afirmaba que los naturales de San Joseph habían sido fieles soldados, según circulaba "entre los hombres antiguos del siglo pasado [...] como testigos de vista". ${ }^{13}$ Recordaban que habían formado un cuerpo de soldados de más de 50 integrantes, que lucharon contra invasiones de indios "guaicurús" y en distintas batallas entre las que resaltaba la de Calchín. Los informantes sostuvieron que estos indios venían sirviendo a su costa sin ración ni sueldo en el fuerte de El Tío, en tiempos de paz y de guerra. ${ }^{14}$ Juan Luis de Funes, quien había ejercido el cargo de comandancia del fuerte de San Carlos de El Tío durante nueve años, afirmó que cuando se llevaban a cabo "fatigas del real servicio" en la frontera para repeler el avance de los abipones, así como para otras correrías y servicios comunes, asistían por orden de Santiago Ramallo indios que decían ser del pueblo de Los Ranchos. ${ }^{15}$

Para considerar la posibilidad de la exoneración del pago del tributo, resulta interesante recuperar los datos brindados por los padrones de tributarios y censos de población. En relación a la cantidad de indios tributarios o en edad
7. AHPC, Esc. 2, Leg. 20, Exp. 17.

8. AHPC, Esc. 3, Leg. 25, Exp. 7.

9. AHPC, Gobierno, cajas 18-19.

10. AHPC, Esc. 2, Leg. 76, Exp. 6, f. 1 r.

11. Es necesario recordar que no contamos con las mismas fuentes para abordar la evolución y composición demográfica del pueblo de indios de San Joseph, pues dejó de registrarse a partir de 1775. En el padrón de 1704 no se consigna la clasificación de los empadronados. En 1733 figuran 7 individuos (de 66) clasificados como mulatos, pardo, chinita o foráneo. Mientras que en 1774 figuran 12 mulatos, 2 forasteros y 3 individuos consignados como "del pueblo" (de 134).

12. La frontera oriental de Córdoba, que incluía al Río Segundo, fue muy afectada por conflictos con naciones de abipones y mocovíes en la primera mitad del siglo XVIII. Según Rustán (2005: 46), esta frontera se habría caracterizado por un estado de conflictividad permanente por las incursiones de grupos indígenas no sometidos. En la misma línea, Tell (2008: 74) recupera referencias sobre la retracción del poblamiento colonial en esta frontera a raíz de las invasiones de las naciones del Chaco, entre 1727 y 1744 . Al respecto, Punta (2001: 173-174) sostiene que las reducciones de mocovíes y abipones fundadas en 1745 y 1747 en la región litoral, en las cercanías de Santa Fe, actuaron como "colchón" protector del territorio cordobés.

13. AGN IX 23-4-5, fs. 22r-23v.

14. AGN IX 23-4-5 fs. 28r-v. Según el testimonio de Bocos, en el marco del juicio por las tierras, los indios servían en las Compañías de Naturales que, como en todas las fronteras de la Gobernación del Tucumán, debían marchar adelante y estar en las primeras filas durante el rompimiento de fuego y sangre. Asimismo, debían realizar otras actividades como recoger palmas para llevarlas a la ciudad en semana santa, trabajar en los cuarteles del presidio de El Tío y recoger ganados del Rey.

15. AGN IX 23-4-5 f. 101r. El pueblo de indios "San Joseph" también fue nominado "Los Ranchos" en varias oportunidades. 
16. AGN, IX 23-4-5, f. 9or.

17. La figura del administrador de encomienda se amparaba en un auto del gobernador Mercado y Villacorta, en relación a las encomiendas de procedencia calchaquí. Según Zelada (2017) esto constituía un ardid que, en la práctica, podría haber significado el ejercicio de una encomienda en tercera vida.

18. AGN, IX 23-4-5, f. 35v. de tributar podemos notar un pequeño crecimiento en 1704, en comparación a los catorce tributarios de 1694 consignados por el oidor Luján de Vargas. Sin embargo, a medida que avanzó la primera mitad del siglo vemos un decrecimiento notable en la cantidad de población masculina, en comparación con las mujeres registradas liderando las unidades censadas. Creemos que esta diferencia, si bien puede relacionarse a un subregistro de la población masculina en edad de tributar, también puede abonar la idea de que la real ausencia de hombres en el pueblo estaría relacionada con sus tareas como soldados.

En el próximo registro, en 1774, ya fue nominado como “Compañía y pueblo de indios Los Ranchos" y en este padrón el censista no resaltó los indios en edad de tributar, a pesar de que su número podría ascender a 41 tributarios. Al hacer la lectura de este padrón, Ana Inés Punta sostiene que "sólo excepcionalmente se señaló en ellos quienes debían tributar" (Punta, 1994: 56). Creemos necesario preguntarnos si, en el caso que estudiamos, el hecho de que el padrón no aclare quiénes eran indios de tasa, a la vez que denomine al pueblo como "compañía", podría deberse al acuerdo -aunque no hemos encontrado que esté documentado- de exoneración del pago del tributo por sus servicios en la frontera. Por otro lado, también nos preguntamos si el gran aumento del número de hombres en edad de tributar podría deberse al efectivo regreso y permanencia de los hombres en el pueblo, una vez pacificada la frontera este.

Ahora bien, como dijimos, San Joseph no aparece en los registros de Real Hacienda de la segunda mitad del siglo, ni fue registrado en ningún otro documento con posteridad a la implementación de las reformas borbónicas ¿Por qué el visitador Florencio Antonio García no registró a este pueblo de indios como tributario en la Jurisdicción de Córdoba?

Por un lado, debemos considerar que a diferencia del caso de San Marcos los habitantes de San Joseph quedaron, a la muerte de su segundo encomendero -después de 1705- y según consta en la cláusula cinco de su propio testamento, en manos de su hijo Vicente Funes. ${ }^{16}$ Como administrador de la encomienda, ${ }^{17}$ Vicente estaba obligado a pagar el tributo a las reales cajas; sin embargo, según la información brindada por Ambrosio Funes -nieto de Vicente- a instancias del juicio, sabemos que éste no se hizo cargo de la administración de la encomienda, a causa de llevar a cabo sus funciones como militar en la frontera. ${ }^{18}$ Tampoco tenemos noticia de que alguien más se haya hecho cargo de esta encomienda. Así, salta a la vista una diferencia fundamental con el caso de San Marcos, que sí contó con un español que medió en el pago del tributo, situación que quedó registrada en documentos de la Real Hacienda. En este sentido, creemos que la presencia de la figura de administradores de encomienda, a medida que estas vacaron, pudo haber tenido alguna importancia en relación a la sistematicidad del entero del tributo que diferenció a estos pueblos ya que, como hemos visto, luego de que la encomienda de San Marcos quedara en manos de la Corona, los habitantes del pueblo de indios entregaron con regularidad su tributo a las reales cajas, por intermedio de su administrador. Esta constancia a lo largo de todo el siglo XVIII quedó cristalizada en el registro, situación que contribuyó positivamente al momento de mantener el reconocimiento oficial de parte de la Corona española y, consecuentemente, defender sus tierras de los avances y apropiaciones de sus vecinos españoles. Creemos que esta diferencia, sumada a la posibilidad de la exoneración a cambio de sus servicios de la frontera, podría haber ido resintiendo su categorización como pueblo de indios tributarios. 
En este sentido, es necesario considerar que la Instrucción Metódica (en adelante, IM) del visitador Escobedo ${ }^{19}$-cuyos lineamientos se siguieron en las revisitas de 1785 y 1792- al igual que los más generales de la ROI, no fueron explícitas con respecto a los indios soldados, aunque sí se manifestó con claridad que todos los indios de la clase tributaria debían registrarse, estuvieran exentos o ausentes, justificando los motivos para cada situación. Aunque se hizo mención a casos especiales por los que determinados grupos quedarían reservados del pago del tributo, no se hizo particular referencia a los indios soldados.

A pesar de este silencio en la IM, contamos con disposiciones previas en el caso de la Gobernación del Tucumán. Punta (1994) advierte que el gobernador Joaquín de Espinosa y Dávalos había establecido en un auto de 1761 que el hecho de que los indios estuvieran sirviendo en compañías o fuertes no era un motivo para exceptuarlos del pago del tributo y solo se eximía a quienes se hallaren en ejercicio de cabos militares (Punta, 1994: 55). Sin embargo, referencias en distintos expedientes de la segunda mitad del XVIII nos permiten inferir sobre la exoneración del pago del tributo por servicios en la frontera o milicias, o viceversa, en Córdoba. ${ }^{20}$ En la misma línea, podemos recuperar información analizada por Ferrero sobre la incorporación voluntaria de indios foráneos y castas como tributarios a los pueblos de indios de Córdoba, con posterioridad a la IM, y la alternancia entre las dos situaciones que manejaban como posibilidad estos individuos. La autora sostiene que en 1797 -con motivo de la discusión sobre la realización de una nueva revisita- los alcaldes ordinarios cuestionaron este tipo de agregados en las listas de 1792, ya que denunciaban que perseguían el objetivo de evitar las fatigas en las milicias (Ferrero, 2017: 132), dando cuenta de que continuaba la práctica de que los servicios en las fronteras y/o milicias exoneraban del tributo y viceversa, aunque las autoridades coloniales percibieran esto como un problema. ${ }^{21}$

La situación estudiada con mayor profundidad, más parecida al caso de San Joseph, es la investigada por Judith Farberman $(2006,2009)$ sobre los pueblos de indios de la línea fronteriza del río Salado, en la región santiagueña, que fueron exentos del tributo a cambio de sus servicios como soldados hacia mediados del siglo XVIII. No obstante, en este caso, esto no implicó la pérdida de los derechos sobre las tierras. Esto sugiere una posible aplicación diferenciada de la ROI y de la IM en distintas jurisdicciones de las gobernaciones intendencias de Salta y Córdoba, ${ }^{22}$ que siguiera tanto costumbres como configuraciones de poder local preexistentes.

El caso de San Joseph nos sirve de ejemplo para pensar en la posibilidad de que una modificación en una categoría de registro -de "pueblo de indios" a "compañía" - y su posterior ausencia -sumada a la falta de un documento probatorio del acuerdo de exoneración- sirvieron de precedentes para que, a fines del siglo XVIII, la administración colonial desconociera la existencia de un pueblo de indios y se propiciasen ciertas condiciones -en los papeles- que sirvieron de base para el posterior avasallamiento de sus derechos coloniales colectivos.

\section{Las autoridades indígenas: legitimidad y rol en la coyuntura de defensa de las tierras de los pueblos de indios}

El último punto que nos interesa trabajar aquí es acerca del rol que cumplieron las autoridades indígenas en la defensa de los derechos de los pueblos de
19. Instrucción metódica del tribunal de Visita General de Justicia y Real Hacienda, para los empadronamientos o revisitas de tributarios de los Virreinatos del Perú y Río de la Plata. Jorge Escobedo, Lima, 01/o7/1784. (Copia consultada en FDPC, Doc. 12466).

20. En 1753, un estanciero vecino del pueblo de indios de Nono advertía sobre la agregación de personas que buscaban evitar las "situaciones de la frontera" (AHPC, Esc. 1, Leg. 317, Exp. 6, f. 84v). En 1766 un mulato que habitaba en las tierras del pueblo de indios de San Esteban de Guamacha sostuvo que "por estar alistado en una de las Compañías de Naturales que ay en este rio le parece que no deve pagar tributo" (AHPC, Esc. 3 , Leg. 35, Exp. 14, f. 526r.), dato por ahora único pero muy sugerente en cuanto a la posibilidad de que se hubiera formado una, compañía -o más- compuesta por indios del Río Segundo en la primera mitad del siglo XVIII. Queda también por responder la duda de si se formaron con indios tributarios de la Corona o con los que todavía formaban parte de encomiendas privadas.

21. La formación de una Compañía de naturales también fue pensada como contraprestación para mantener los derechos sobre las tierras en un caso de Buenos Aires: el pueblo de indios de Santiago de Baradero. De hecho, sus habitantes se resistían a la creación de una villa de españoles sobre esas tierras, ofreciendo "formar una compañía de naturales y volver a pagar tributo", aunque esto no fue concedido (Canedo, 2016: 17).

22. Agradecemos esta observación a Isabel Castro Olañeta. 
23. Los encontramos con los apellidos Diguala, Piguala y Pibala, a partir de la reconstrucción de la genealogía familiar hemos concluido que se trata de deformaciones del apellido del mismo grupo familiar.
24. Zelada (2017: 136) sostiene que el cacique de La Toma podría tener como estrategia de defensa hacia los desnaturalizados calchaquíes repartidos en la jurisdicción el asilo de los indios huidos de las encomiendas en La Boca Toma de la ciudad, donde poseían condiciones diferenciales al estar al servicio de la ciudad y no un encomendero.

25. Esta información coincide, en líneas generales, con la expuesta por González Navarro (2015: 168) cuando expone la genealogía de los Pibala que pudo reconstruir a partir de la consulta de las actas de nacimiento y matrimonio del curato de Villa del Rosario. indios. Para esto, además, recuperaremos los procesos de conformación de las autoridades indígenas. Serulnikov (2004) nos invita a pensar en los criterios de legitimidad política de las autoridades indígenas en el siglo XVIII, remarcando la importancia de trabajar a partir de estudios de casos locales que den cuenta de los particulares contextos sociales y que se alejen de generalizaciones abstractas para todo el espacio colonial (Serulnikov, 2004: 71). En este sentido, si bien no contamos con documentos que nos permitan conocer su accionar o negociaciones en relación a los procesos que mencionamos a lo largo de todo el siglo XVIII, tanto el curaca de San Joseph como el de San Marcos se involucraron e incluso encabezaron los procesos judiciales para procurar la restitución de las tierras, a fines de ese siglo. Los expedientes judiciales de fines del siglo nos permiten aproximarnos, un poco más, a los curacas así como a otras autoridades en estos pueblos de indios.

El expediente por las tierras de San Joseph inicia con un pedido de su curaca ante la Audiencia de Buenos Aires, solicitando que se hiciera lugar a los testimonios de personas que presentaba junto a un interrogatorio en relación a la historia de este pueblo de indios en esas tierras. Se trataba de Don Estanislao de la Cruz Pibala quien, en una de las preguntas, hizo referencia a la historia de su familia manteniendo la línea de cacicazgo.

Así, nos preguntamos acerca de la legitimidad que esta familia gozaba en el pueblo de indios y su presencia como agente articulador de la comunidad a lo largo del siglo XVIII. Como dijimos anteriormente, se trata de un pueblo de indios conformado a partir una encomienda de indios calchaquíes desnaturalizados. Zelada (2017) encuentra la primera referencia a esta familia ${ }^{23}$ ejerciendo como autoridad en el acto de entrega de posesión de la encomienda, en 1688 (Zelada, 2017: 135). Posteriormente, en 1693, cuando Luján de Vargas visitó la encomienda en la estancia de su encomendero, el mismo cacique -don Juan Piguala, de 66 años- denunció estar habitando en tierras de la estancia de su encomendero, además de denunciar que éste los obligaba a trabajar para él -sin recibir paga ni prendas de vestir-. Manifestó que no acudía a instancias judiciales "porque conoce que no a de conseguir justicia y a lo de sauer el encomendero y se a de enojar y en este lugar se ayudan todos los espanoles los unos a los otros y no ay quien faboresca a los yndios" (Bixio et al., 2009: t. I, 347). No obstante, Zelada sugiere, para estos años, un vínculo entre Piguala y el cacique del pueblo de indios de La Toma, Francisco Sillamay. ${ }^{24}$ A raíz de la denuncia del propio encomendero parecería que Sillamay, al gozar de mayores libertades por no estar bajo el sistema de encomienda privada, habría actuado como agente cohesionador de los grupos desnaturalizados y sí habría acudido a autoridades españolas jerárquicas a denunciar el abuso del sector encomendero. En efecto, Funes desmereció las denuncias de sus encomendados apoyándose en una supuesta persuasión de parte del cacique de La Toma (Zelada, 2017: 135).

Aun cuando no tenemos más referencias de esta posible historia en común entre ambos caciques, sí encontramos la continuidad en el traspaso del mando del pueblo de San Joseph, siempre en manos de la misma familia. La información provista por padrones y censos de población nos permiten reconstruir el árbol genealógico de los Pibala, hasta llegar a Estanislao de la $\mathrm{Cruz}_{,}{ }^{25}$ quien intervino activamente en el juicio a fines del XVIII. Es decir que, desde la llegada de esta parcialidad a la jurisdicción de Córdoba hasta comienzos del siglo XIX, el linaje Pibala mantuvo el curacazgo en sus manos. Aunque no conocemos el origen de esta familia en el cargo, podemos decir que la legitimidad de los Pibala como autoridad en este pueblo de indios se relaciona con 
el criterio de sucesión por sangre y, además, con su actividad en la defensa de los intereses de sus habitantes.

Si consideramos que el gobierno de los pueblos de indios debía componerse, además, de un cabildo indígena, debemos decir que en San Joseph no hemos encontrado ninguna referencia a su constitución. Como contrapartida, y en estrecha relación a la particular historia de este pueblo y Compañía de indios, sí hemos identificado a otros cargos ejerciendo alguna función de autoridad. Nos referimos particularmente a la mención de Cosme Damián Funes, ${ }^{26}$ presentado tanto en los expedientes iniciados por el reclamo de las tierras del pueblo de indios (entre 1790 y 1800) como "Capitan de la campaña de milicias", "capitan de naturales", "capitan del pueblo" e "indio capitan del pueblo de Los Ranchos". ${ }^{27} \mathrm{Si}$ bien es importante recuperar el título en sí, en tanto así lo referenciaron las autoridades coloniales, más nos interesa recalcar que fue esta persona quien, en varias ocasiones, fue citada o notificada de acciones o modificaciones de la situación en que se encontraba el expediente judicial; es decir, que fue él quien actuó como representante o interlocutor de la comunidad frente a las autoridades externas. Esta información adquiere mayor relevancia si consideramos que, por esos años, el curaca Estanislao de la Cruz Pibala se encontraba en Buenos Aires, litigando en la Real Audiencia. Esta situación nos muestra la existencia de un acuerdo interno para que el capitán gozara de jerarquía, no solo en relación al reconocimiento oficial de los funcionarios coloniales, sino también para con la comunidad.

En efecto, en 1790 es él mismo quien presentándose como "indio capitan del pueblo de los Ranchos, situado en el Rio Segundo, en el que tanbien exerzo las funciones de curaca" ${ }^{28}$ escribe una carta al Gobernador Intendente en la que denuncia la perturbación de la que eran víctimas por la invasión de sus tierras de parte del vecino español. Asimismo, en 1795 Cosme Damián fue notificado de que debían presentar los títulos en los que basaban sus derechos a las tierras que ocupaban, también fue él quien congregó a otros habitantes del pueblo de indios para participar de la mensura realizada ese año, junto a otros vecinos colindantes. En esa ocasión, "el capitan, teniente y demas habitantes del referido pueblo fueron mostrando y SS reconociendo y combenidos todos sin la mas pequeña disputa en los linderos que de parte a parte mostraron $[\ldots]^{\prime \prime}{ }^{29}$

Entonces, nos parece importante remarcar la estrategia del pueblo de indios para coordinar las acciones de dos autoridades actuando en su representación, en dos espacios distintos y distantes. Igualmente importante nos parece el hecho de sostener una doble representación en una misma figura, como era la de Cosme Damián. Como vimos, en ausencia del curaca, fue él quien ejerció el cargo y estuvo al frente de la defensa de las tierras del común que correspondían al pueblo de indios. Pero, además, no se dejó de remarcar que se trataba de un capitán, apelando al cargo militar que permitiría demostrar que también constituían una compañía de indios soldados y que esa situación era la que les permitiría argumentar su falta en el pago del tributo. Así, aunque hacia fines del siglo, en términos militares, el título de "capitán de la compañía" no habría tenido mayor importancia, en tanto para ese momento el área dejó de implicar la necesidad de defensa, ${ }^{30}$ dicho título tenía relevancia ya que rememoraba el particular acuerdo que este pueblo de indios habría hecho en relación a sus prestaciones para la Corona, conmutando el pago del tributo por sus servicios como Compañía de indios soldados.

En el caso de San Marcos, por su parte, es la familia Tulián la que encabeza la defensa de las tierras del pueblo de indios. Sin embargo, su presencia entre
26. En distintos documentos lo encontramos con el nombre de Cosme Damián Funes, Damián Mattos o Cosme Damián Matos. La contrastación de datos del grupo familiar en distintos padrones nos permite asegurar que se trata de la misma persona.

27. Recordemos que se trata de un pueblo de indios que, en la primera mitad del siglo XVIII, había servido en la defensa de la frontera este, por lo tanto este título respondería a un cargo jerárquico dentro de la Compañía de indios soldados.

28. AHPC, Esc. 2, Leg. 76, Exp. 6, f. 5v.

29. AGN, IX 23-4-5, f. 65r.

30. Hacia la segunda mitad del siglo XVIII, el área habría dejado de responder a las características de una frontera para pasar a ser una zona con una relativa consolidación, ya sea por el cese de malocas de grupos chaqueños que posibilitó una estabilidad mayor en la cantidad de población que albergaba como por la consolidación de su orientación productiva (Schibli, 2015). 
31. En ese periodo también accedieron al cargo Francisco Xavier Bazán (en 1768) y Pablo Antonio Luján (en 1785); este último había sido regidor y alcalde varios años antes de ocupar el cargo y además defendió las tierras del pueblo de indios frente a los apoderados de los propietarios absentistas de la estancia vecina de San Marcos.

32. AGN, IX 31-7-8. f. 35r.

33. AGN 34-7-5 s/f.

34. Según Piana (1992) Tulián sería un topónimo correspondiente a un pueblo de las sierras norte, mientras Montes (2008: 622) también identifica a este topónimo como propio de noroeste de Córdoba.

35. Para la Jurisdicción de Córdoba no contamos con estudios específicos sobre los procesos de conformación y acceso a los cargos, ni los cambios introducidos por las instituciones españolas respecto a los modos prehispánicos de nombramiento y sucesión, tampoco sobre los lazos y la relación que curacas, alcaldes y regidores tenían con el resto de la comunidad reducida en los pueblos de indios. las autoridades indígenas comienza a registrarse a fines del siglo XVIII y, a lo largo del periodo estudiado, hemos podido identificar a otras familias ejerciendo el curacazgo.

Recordemos que también se trata de un pueblo de indios conformado a partir de una encomienda de indios calchaquíes -yocaviles-, que habían sido desnaturalizados y trasladados inicialmente a La Rioja y luego a Córdoba. En los padrones levantados en Córdoba a fines del siglo XVII no se consignó la presencia de ningún curaca que hubiere llegado junto al grupo desnaturalizado.

Sin embargo, en otra encomienda visitada en La Rioja, que habría sido desnaturalizada en la misma campaña militar que la encomienda de Luján de Medina, en 1667 sí aparece un curaca yocavil llamado Pedro Uchunga (Boixadós, 2011: 8; Zelada, 2017: 139). Esta información nos interesa en tanto la primera referencia a una autoridad étnica en San Marcos es la del cacique principal Manuel Ochonga, en 1749. Creemos que la similitud de los nombres podría dar cuenta de alguna familiaridad de este curaca con la línea cacical de la parcialidad yocavil asentada en La Rioja (Zelada, 2017: 166).

Hasta 1768 no encontramos otros registros que den cuenta de la presencia de curacas en este pueblo de indios, y entre ese año y 1794 el curacazgo pasó por distintas manos, alternándose entre la familia Ochonga y otras ${ }^{31}$ cuando no había herederos de sangre de ésta, o los descendientes eran aún menores de edad.

En el mismo sentido es que, entre 1794 y 1795 "en defecto de no haverlo de la sangre", 32 el gobernador intendente Sobremonte nombró a Francisco Tulián, quien ya se había desempeñado en el cabildo indígena, al igual que su padre Manuel y su hermano José Leandro. A partir de este momento, encontramos un periodo de estabilidad del cargo del curaca en manos de una misma persona, sin nombramientos interinos. Solo identificamos una breve interrupción en el año 1804, cuando José Antonio Tulián tomó el cargo mientras Francisco Tulián, su padre, había viajado a Buenos Aires con motivo de la defensa de las tierras del pueblo de indios. A su regreso, Francisco Tulián retomó sus funciones como curaca hasta su muerte en 1808, cuando José Antonio fue nombrado por el capitán recaudador del tributo Jacinto Roque Olmos y los regidores del pueblo. ${ }^{33}$

Si bien no tenemos información sobre el modo en que la familia Tulián llegó a ejercer cargos en el gobierno de San Marcos, sabemos que se trata de un topónimo originario de Córdoba ${ }^{34}$ por lo que no se trataría de una autoridad asociada a liderazgos previos a la dominación de los grupos calchaquíes sino quizá a familias de indios originarios de la jurisdicción, integrados al pueblo de indios.

Los casos analizados nos llevan a preguntarnos sobre los modos en que las personas accedieron y ejercieron sus funciones como autoridades en los pueblos de indios de la jurisdicción de Córdoba, teniendo en cuenta la legitimidad que gozaban tanto al interior del pueblo de indios como frente a los funcionarios coloniales. $^{35}$

Dado que ni en la Visita de Luján de Vargas ni en otros documentos tempranos se indagó acerca de los derechos de las autoridades indígenas ejerciendo cargos, creemos que las autoridades étnicas, bajo las nuevas lógicas de dominación colonial, se originaron o reconfiguraron a partir de la necesidad de 
crear y desplegar nuevas estrategias de pervivencia, sin desconocer las posibles continuidades en las líneas cacicales (Zelada, 2017: 163; Schibli y Zelada, 2017).

Tell plantea que el final del proceso de conversión de encomiendas privadas a pueblos de indios tributarios de la Corona, hacia mediados del siglo XVIII y en adelante, fortaleció a las autoridades en tanto se les asignaron tareas en el empadronamiento, cobro del tributo y administración de la justicia (Tell, 2017). La ROI del Río de la Plata (1782) no explicitó las funciones para los curacas, pero en actas de nombramientos o en pleitos criminales en los que eran acusados, revisadas por Tell (2018), se deja entrever que se les atribuían funciones judiciales y de policía y que se los incriminaba cuando no velaban por el orden en sus comunidades. Además, curacas y alcaldes recibían las querellas de los vecinos contra los indios, directamente o por intermediación de autoridades españolas (Tell, 2018: 10-11). En relación al nombramiento de curacas, Tell y Ferrero (2015) han identificado distintas modalidades que aún no se estudiaron en profundidad. En principio, el cargo debía recaer en aquellos indios a quienes les correspondiera como herederos de sangre, siguiendo los principios del mayorazgo español. Sin embargo, las autoras han encontrado curacas nombrados de manera interina. Se trata de casos en los que el gobernador intendente intervenía en el gobierno del pueblo de indios para nombrar a un sujeto que ocupara el cargo. Era habitual que para decidir sobre quién iba a recaer el nombramiento, el gobernador intendente pidiera colaboración del capitán recaudador del tributo. Del mismo modo, las autoridades españolas y el propio capitán recaudador podía pedir la remoción del curaca cuando considerara que no satisfacía la función. (Ferrero, 2017; Tell, 2018)

Los casos analizados abonan ambos mecanismos considerados en esta hipótesis: en San Joseph, como hemos visto, el cargo de cacique se mantuvo de manera hereditaria en manos de la misma familia, desde su constitución como encomienda hasta desaparecer de los registros, a principios del siglo XIX. Por su parte, el caso de San Marcos es más complejo dado que el acceso al cargo de curaca también siguió la línea familiar, por lo menos en el siglo XVIII, aunque esta forma de proceder fue interrumpida cuando no había heredero por sangre o este era menor de edad. Según vimos, solo una vez la sucesión fue, con seguridad, en mandatos consecutivos y de padre a hijo. Creemos que fue igualmente habitual que al encontrarse vacante el cargo -por fallecimiento de la autoridad sin descendencia o por renuncia-, las autoridades españolas pudieran intervenir en el nombramiento de curacas interinos. Si bien la información con la que contamos es fragmentaria, suponemos que la elección de las personas que actuarían como curacas interinos fue fruto de consensos negociados con los funcionarios coloniales, en los que los miembros del cabildo indígena pudieron imponerse, y el cargo recayó en personas que, en ejercicio de sus funciones, velaron por la defensa de los derechos del pueblo de indios. ${ }^{36}$

En relación al cargo de alcalde, solo contamos con la información provista por los documentos de San Marcos los cuales dejan en evidencia que era muy común que las mismas personas lo ejercieran en varios periodos $\mathrm{y}$, además, que esas personas tuvieran vínculos familiares. ${ }^{37}$ Asimismo, era habitual que, luego de haber actuado como alcalde, se sostuvieran como regidores y que, consecuentemente, los cargos de gobierno del pueblo de indios siempre quedaran en manos de las mismas familias y personas.

Una última cuestión importante de remarcar es la importancia que también tomó el cabildo indígena en San Marcos, en tanto hemos notado no solo su presencia y renovación periódica hacia fines del siglo XVIII sino también su
36. A pesar de no contar con documentos que nos permitan afirmar que los nombramientos del curacas interinos, como Francisco Tulián, fueron fruto de negociaciones entre funcionarios españoles -los capitanes recaudadores- y los miembros del cabildo indígena, creemos que esto es plausible en tanto el cargo nunca recayó en manos de una figura que su comunidad haya denunciado por abusos o malos tratos. Por el contrario, además de recaer en personas que antes cumplieron funciones en el cabildo indígena, los encontramos actuando ininterrumpidamente en la gestión y defensa de los recursos comunes del pueblo.

37. El ejemplo más evidente es el caso de la familia Tulián. Manuel Tulián fue el primero de esta familia que encontramos ejerciendo el cargo en 1768, posteriormente, uno de sus hijos, Francisco Tulián, lo ejerció en 1785 antes de ser curaca. José Leandro Tulián, otro de sus hijos, lo ejercería por primera vez en 1787 y luego en 1792, 1793 y 1797. 
38. AHPC, Esc. 3, Leg. 6o, Exp. 2, f. 1r. El resaltado en cursiva es nuestro.

39. AHPC, Esc. 3, Leg. 6o, Exp. 2, f. $2 \mathrm{r}$ intervención con acciones concretas, como la de consentir el nombramiento de un curaca. Del mismo modo, en 1812 los regidores, acompañados por una larga lista de miembros de la comunidad, se manifestaron en un conflicto entre el curaca y el alcalde por una huerta; no solo se posicionaron sino que aclararon haber sido ellos quienes arrendaron la huerta al curaca, a fines de que éste afrontara los costos del comisionado que actuó en las diligencias por la recuperación de sus tierras:

Decimos que es verdad que haora meses pasados vluntariamente, y de unanime
consentimiento le arrendamos una huerta compuesta de varios arboles frutales
en la cantidad de treinta y sinco pesos que exivio de su volsillo para la solucion
de las costas que se nos hizo cargo por el superior Govierno a favor del
comicionado Do Ramon Caseres por haver este señor evacuado las diligencias
para la pocecion de nuestros terrenos. ${ }^{38}$

En el mismo expediente, Francisco Tulián hace su descargo manifestando que, en ocasión de decidir sobre los gastos y recursos del pueblo, tuvo "por conveniente juntar [al] mi cavildo y demas comunidad por tres ocaciones". En consonancia con la versión de los miembros del cabildo, el resultado en voz publica fue arrendar por un año una huerta con árboles frutales que eran de usufructo de la comunidad. ${ }^{39}$

Lo interesante de este documento es que no solo podemos ver al curaca involucrado en la administración de los recursos comunes del pueblo de indios, y en cómo solventar gastos ocasionados por la defensa de esos recursos sino que nos muestra que los habitantes de San Marcos participaban de reuniones, convocadas por el curaca, en las que la comunidad era habilitada para tomar tales decisiones.

Esto nos lleva a pensar que, a fines del XVIII y principios del siglo XIX, la legitimidad de las autoridades indígenas recaía, más que en principios de sucesión hereditaria del cargo, en la construcción de acuerdos al interior de una comunidad. Asimismo, la constitución del cabildo indígena pudo significar la posibilidad de dar espacio a la participación de más miembros de la comunidad en la toma de decisiones aunque, como vemos, no se restringió a esa institución.

En síntesis, podemos pensar que su reconocimiento a partir del criterio de mayorazgo, o incluso por el hecho de tratarse de familias que podrían haber ejercido el liderazgo en su historia previa al sometimiento, no era necesario ni suficiente, en las últimas décadas del siglo XVIII y principios del XIX, para erigirse como autoridades representativas. Creemos que más importante fue la capacidad que estas tuvieron para administrar los recursos de la comunidad, regular conflictos internos y externos, actuar en pos de la defensa de los derechos del pueblo de indios y, como lo sugiere el caso de San Marcos, abrir espacios para la participación de un núcleo relativamente amplio de familias en la generación de consensos y toma de decisiones. Así, consideramos que la legitimidad política estaba fuertemente vinculada a la reproducción social de la comunidad y, en consecuencia, a la administración de los recursos que producían. En este sentido, espacios que garantizaran la representatividad de la autoridad serían fundamentales para su sostenimiento en el cargo.

Como hemos visto, si bien en los dos casos analizados nos encontramos con autoridades defendiendo un recurso imprescindible para la comunidad, como lo es la tierra, nos preguntamos si la manera en la que en San Marcos 
descansaba la relación comunidad-autoridades indígenas -que no observamos en el caso de San Joseph- pudo haber repercutido positivamente en el desenlace de los conflictos de este pueblo de indios.

\section{Reflexiones finales}

Como hemos adelantado, a fines del siglo XVIII y principios del XIX, en las tierras de San Joseph se avanzó en la fundación de una villa de españoles, en desmedro de los derechos colectivos de las personas que habitaban este pueblo de indios. En cambio, la comunidad de San Marcos logró, en la misma coyuntura, recuperar tierras que a lo largo del siglo XVIII había ido perdiendo.

¿Por qué en uno de los casos se logró sostener el reconocimiento oficial del pueblo de indios y sus derechos, mientras que en el otro no? Abordar la historia de San Marcos y San Joseph desde una perspectiva comparativa nos permite aproximarnos a algunas consideraciones respecto a los desenlaces divergentes de sus historias.

En primer lugar, es importante recuperar la capacidad que ambos pueblos de indios tuvieron para crecer a largo de todo el siglo XVIII, mayormente a través de la incorporación de población foránea: mestizos, castas e indios originarios de otros pueblos, contribuyendo a la reproducción y supervivencia de la comunidad. Asimismo, la movilidad interna de forasteros sin tierras a la categoría de originarios y forasteros con tierras, consignada para el caso de San Marcos en las revisitas borbónicas, nos permite pensar en una estrategia implementada para fortalecer el núcleo de indios con acceso a las tierras comunales, mantener la ocupación efectiva de las mismas y afrontar el pago del monto colectivo del tributo, aunque se desconocen las particularidades de esta incorporación (Ferrero, 2012). Para el caso de San Joseph, si bien sabemos que desde la primera mitad del siglo XVIII incorporó población foránea al pueblo, no contamos con registros que permitan conocer la movilidad interna de sus habitantes ya que, como dijimos, este pueblo no fue registrado en las revisitas borbónicas.

En este sentido, hemos sugerido que, a pesar de las similares conformaciones de ambos pueblos de indios y de similares situaciones demográficas, las maneras particulares en que se planteó la relación con la Corona, en particular la forma que asumió el tributo en cada caso, fueron fundamentales a la hora de luchar por sus derechos. Mientras San Marcos mantuvo con constancia el cumplimiento de su obligación tributaria -y esto, además, consta en los documentos a lo largo de todo el siglo XVIII, constituyendo el paso de encomienda privada a tributarios en la cabeza de la Corona una coyuntura crucial en esa continuidad-, la existencia del pueblo de indios de San Joseph fue cuestionada justamente por no hacerlo. Recordemos que a diferencia de San Marcos, no se registró el pago del tributo por parte de ningún administrador de San Joseph en el proceso de conversión a tributarios en cabeza de la Corona. Y que, lo particular de este caso radica en la posibilidad de que los indios y las autoridades coloniales de la primera mitad del XVIII hubieren negociado la exoneración del pago de la tasa a cambio de sus servicios en la defensa de la frontera, situaciones que -conjugadas- habrían resentido su reconocimiento como pueblo de indios a medida que avanzó el siglo, teniendo como corolario la fundación de una villa de españoles sobre esas tierras, impulsada por las autoridades coloniales. A pesar de que las autoridades y los habitantes de San Joseph acudieron a la justicia y llevaron una férrea defensa de sus derechos e 
intereses colectivos, la falta de documentación que demostrara este probable acuerdo así como la ausencia de sus habitantes en los registros de tributarios contribuyeron a desacreditar su versión.

Por otro lado, hemos abordado los procesos de conformación y legitimación de los caciques, y otros cargos de gobierno indígena, al interior de estos pueblos de indios. De este análisis se desprende que las autoridades indígenas debieron reconfigurarse bajo la situación de dominación y, hacia mediados del siglo XVIII, no bastaba con que los curacas se apoyaran en el criterio de mayorazgo español para el acceso al cargo. La gestión de los recursos, la administración de la justicia, la defensa de sus derechos y la habilitación de espacios de participación para un número más amplio de familias en la toma de decisiones fueron fundamentales para obtener la legitimidad política. El caso de San Marcos daría cuenta de una relación entre las autoridades y la comunidad en este sentido, que pudo también haber jugado un papel importante en la coyuntura de vulneración de sus derechos colectivos a las tierras y en la estrategia defensiva implementada, logrando un fallo favorable. Creemos que analizar el rol y la legitimidad de las autoridades étnicas en las lógicas del mundo colonial constituye una de las claves significativas a la hora de estudiar la persistencia de las comunidades, en tanto las encontramos trabajando de forma sistemática en la defensa de los intereses de sus pueblos de indios. Sin embargo, el éxito de sus estrategias dependió de la capacidad que tuvieron para negociar su reconocimiento tanto al interior de sus comunidades como frente a las autoridades coloniales. 


\section{Fuentes consultadas}

» Fondo Documental Pablo Cabrera (FDPC)

FDPC, Padrón de indios tributarios 1704, Doc. 3357.

FDPC, Doc. 12466. Instrucción metódica del tribunal de Visita General de Justicia y Real Hacienda, para los empadronamientos o revisitas de tributarios de los Virreinatos del Perú y Río de la Plata. Jorge Escobedo, Lima, 01/o7/1784. (Copia)

»Archivo Histórico de la Provincia de Córdoba (AHPC)

AHPC, Esc. 1, Leg. 317, Exp. 6, f. 84v.

AHPC, Esc. 2, Leg. 20, Exp. 17.

AHPC, Esc. 2, Leg. 76, Exp. 6, f. 1r. y f. 5v.

AHPC, Esc. 3, Leg. 25, Exp. 7.

AHPC, Esc. 3, Leg. 35, Exp. 14, f. 526r.

AHPC, Esc. 3, Leg. 6o, Exp 2. f. 1 y y 2 r.

AHPC, Gobierno, cajas 18-19.

AHPC, Hacienda 4 (1765-1770)

AHPC, Hacienda 11 (1772).

»Archivo General de la Nación (AGN)

AGN, IX 23-4-5, fs. 22r-23V; 28r-v.; 35v; 65 r; 9or; $101 r$.

AGN, IX 31-7-8. f. 35r.

AGN, 34-7-5 s/f. 


\section{Q Bibliografía}

》 Arcondo, A. (1992). El ocaso de una sociedad estamental. Córdoba entre 1700 y 1760. Córdoba, DGP-UNC.

» Bixio, B. (dir.); C. González Navarro.; R. Grana y V. larza (2009). Visita a las encomiendas de indios de Córdoba. 1692-1693. Transcripción y estudios sobre la visita de Antonio Martines Luxan de Vargas. Tomo I. Córdoba, Centro de Estudios Históricos “Prof. S. A. Segreti”. Editorial Brujas.

» Boixadós, R. (2011). El fin de las guerras calchaquíes. La desnaturalización de la nación yocavil a La Rioja (1667) Corpus. Archivos virtuales de la alteridad americana. I (I): 1-16. Disponible en internet: http://ppct.caicyt.gov.ar/index.php/corpus/article/view/250. Consultado el: 15 de noviembre de 2018.

»Castro Olañeta, I. (2015). El oidor de Charcas, Antonio Martínez Lujan de Vargas, y la nueva coyuntura a fines de siglo XVII en el Tucumán. A propósito de los derechos a la tierra de los pueblos de indios. Memoria Americana 23 (1):39-67. 2015. Buenos Aires. Disponible en internet: http://ppct.caicyt.gov.ar/index.php/memoria-americana/article/ view/5888/6185. Consultado el: 15 de noviembre de 2018.

" Celton, D. (1993). La población de la Provincia de Córdoba a fines del siglo XVIII. Buenos Aires, Academia Nacional de la Historia.

»Canedo, M. (2016). Los “pueblos de españoles" en la monarquía hispánica. La ampliación de jurisdicciones hacia el autogobierno (Buenos Aires, siglo XVIII y primeros años del XIX). Prohistoria XIX (25): 1-27.

»Farberman, J. (2006). Los caminos del mestizaje. Tributarios, soldados, indios libres y gentiles en la frontera chaqueña 1700-1810. Estudos de História 13 (2): 177-206.

» Farberman, J. (2009). Las márgenes de los pueblos de indios. Agregados, arrendatarios y soldados en el Tucuman colonial. Siglos XVIII y XIX Nuevo Mundo Mundos Nuevos [En línea], Coloquios. Disponible en Internet: http://journals.openedition.org/ nuevomundo/57474. Consultado el: 15 de noviembre de 2018.

"Ferrero, P. (2012). “Adaptación y resistencia en los pueblos de indios de Córdoba en las últimas décadas coloniales: Estructura interna, tributo y movilidad poblacional”. Trabajo Final de Licenciatura en Historia. Córdoba, Escuela de Historia, Facultad de Filosofía y Humanidades, Universidad Nacional de Córdoba. (Inédito)

» Ferrero, P. (2017). Adaptación y resistencia. Estructura interna, tributo y movilidad poblacional en los pueblos de indios de Córdoba en las últimas décadas coloniales. Buenos Aires, Prometeo.

» González Navarro, C. (2015). "Los indios desnaturalizados del Valle Calchaquí en Córdoba: de rebeldes a fieles soldados del pueblo de San Joseph de los Ranchos (siglos XVII- XVII-XVIII)" en Salazar, J. (comp.), Condiciones de posibilidad de reproducción social en sociedades prehispánicas y coloniales tempranas en las sierras pampeanas (República Argentina): 151-176. Córdoba, Centro de Estudios Históricos Prof. Carlos S. A. Segreti.

" Montes, A. (2008). Indígenas y conquistadores de Córdoba. Buenos Aires, Ediciones Isquitipe.

"Piana, J. (1992). Los indígenas de Córdoba bajo el régimen colonial 1570-1620. Córdoba, Ediciones del Autor. 
»Platt, T. (1982). Estado boliviano y ayllu andino. Tierra y tributo en el norte de Potosí. Lima, Instituto de Estudios Peruanos.

» Punta, A. I. (1994). La tributación indígena en Córdoba en la segunda mitad del siglo XVIII. Andes. Antropología e Historia 6: 49-78.

»Punta, A. I. (2001). Córdoba y la construcción de sus fronteras en el siglo XVIII. Cuadernos de Historia, Serie Economía y Sociedad 4: 159-194.

» Rustán, M. E. (2005). De perjudiciales a pobladores de la frontera. Poblamiento de la frontera sur de la gobernación intendencia de Córdoba a fines de siglo XVIII. Córdoba, Ferreyra Editor.

»Schibli, M. (2015). “De traslados y despojos: historia de las tierras del pueblo de indios de San Joseph en Río Segundo". Ponencia presentada en el XVI Encuentro de Historia Regional Comparada. Red PIHSER - CEPIHA/UNSA - ICSOH/CONICET. Salta, 4 al 6 de junio.

»Schibli, M. (2016). "Versiones acerca de la apropiación del territorio indígena: el caso del pueblo de indios de San Marcos en el siglo XVIII". Ponencia presentada en el II Congreso Internacional Los Pueblos Indígenas de América Latina. Universidad Nacional de La Pampa (UNLP). Santa Rosa, 20 al 24 de septiembre.

» Schibli, M. y V. Zelada (2017). Autoridades étnicas y pueblos de indios en la larga duración. Derrotero y persistencia de los pueblos de indios de San Marcos y San Joseph en Córdoba, fines del siglo XVII y XVIII. Ponencia presentada en el Encuentro de Jóvenes Investigadores/14. Fundación El Colegio de Santiago, CONICET/ FHCSyS - INDES-UNSE. Santiago del Estero, 11 al 13 de octubre

"Serulnikov, S. (2004). Legitimidad política y organización social en las comunidades indígenas de la provincia de Chayanta (siglo XVIII). Anuario de Estudios Americanos 61, T. I.

» Tell, S. (2008). Córdoba rural, una sociedad campesina (1750-1850). Buenos Aires, Prometeo.

» Tell, S (2012). Conflictos por tierras en los 'pueblos de indios' de Córdoba. El pueblo de San Marcos entre fines del siglo XVII y principios del siglo XIX. Andes. Antropología e Historia 23 (1): 71-103.

»Tell, S (2018). Autoridades y conflictos de jurisdicción en “pueblos de indios”. Córdoba, Gobernación del Tucumán, 1750-1810. Revista Complutense de Historia de América 44: 163-186.

» Tell S. e I. Castro Olañeta (2011). El registro y la historia de los pueblos de indios de Córdoba entre los siglos XVI Y XIX. Revista Del Museo De Antropología, 4 (4): 235-248. Disponible en Internet: https://revistas.unc.edu.ar/index.php/antropologia/article/view/5484. Consultado el: 15 de noviembre de 2018.

» Tell, S. y P. Ferrero (2015). El gobierno de los pueblos de indios: autoridades, jurisdicciones y competencias. Córdoba, segunda mitad del siglo XVIII. Ponencia presentada en el Encuentro de Jóvenes Investigadores/13. Fundación El Colegio de Santiago, CONICET/ FHCSyS - INDES-UNSE. Santiago del Estero, 7 al 9 de octubre.

»Zelada, V. (2017). “El mundo desnaturalizado del Calchaquí en las encomiendas y pueblos de indios de Córdoba entre fines del siglo XVII y principios del siglo XVIII”. Trabajo Final de Licenciatura en Historia, Escuela de Historia, Facultad de Filosofía y Humanidades, Universidad Nacional de Córdoba, Argentina. (Inédito) 